\title{
Quantifying the effects of reciprocal assimilate and water translocation in a clonal plant by the use of steam-girdling
}

\author{
Mark van Kleunen and Josef F. Stuefer
}

van Kleunen, M. and Stuefer, J. F. 1999. Quantifying the effects of reciprocal assimilate and water translocation in a clonal plant by the use of steam-girdling. Oikos 85: 135-145.

\begin{abstract}
Experimental studies have shown that clonal plants can reciprocally translocate assimilates and water between interconnected ramets, if grown in heterogeneous environments with complementary resource supplies. Internal exchange of different resources between spatially scattered ramets is a unique trait of clonal plants which can considerably enhance their performance in terms of biomass and clonal of fspring production. Cost-benefit analyses have often been used to quantify the effects of clonal integration. The classical version of this analysis, however, is not applicable to the translocation of different resources in two directions, because each ramet can serve as a sink and as a source at the same time. We used steam-girdling to disentangle and to quantify the effects of reciprocal assimilate and water translocation. This method specifically disables assimilate transport, while leaving water integration unaffected.

We grew ramet pairs of the clonal herb Potentilla anserina in spatially heterogeneous environments with complementary availabilities of light and water. The stolon connection between ramets was left intact, steam-girdled or severed.

Total biomass and clonal offspring production was highest when the stolon connection was left intact, intermediate when it was steam-girdled and lowest when it was severed, confirming our hypothesis that the degree of clonal integration is positively correlated with plant performance. Cost-benefit analyses revealed that ramets benefited significantly from assimilate and water import. Costs of resource export were absent or small. Fully integrated ramets specialized functionally in the uptake of a locally abundant resource. The degree of functional specialization decreased from intact to steam-girdled and severed ramet pairs. Disconnected ramets specialized in the uptake of the locally most limiting resource.

Our results provide evidence that interconnected ramets of $P$. anserina can benefit from bi-directional resource translocation, and that the scale of these benefits is related to the type and degree of physiological integration within clonal fragments.
\end{abstract}

M. van Kleunen and J. F. Stuefer, Dept of Plant Ecology \& Evolutionary Biology, Utrecht Univ., Sorbonnelaan 16, NL-3584 CA Utrecht, The Netherlands (present address of MvK: Institut für Umweltwissenschaften, Universität Zürich, Winterthurerstraße 190,CH-8057 Zürich, Switzerland [vkleunen@uwinst.unizh.ch]).

Stoloniferous herbs with long internodes between ramets are likely to experience environmental heterogeneity by establishing interconnected ramets in patches which differ in resource supply (Eriksson 1986a, Lau and Young 1988, Waite 1994, Shumway 1995). Physiological integration can buffer clonal plants against spatial heterogeneity, as ramets in unfavourable patches can be supported by ramets in more favourable patches (Pitelka and Ashmun 1985, Marshall 1990, Marshall and Price 1997).

Most resource integration studies on clonal plants were based on the assumption that heterogeneous environments consist of patches that are either favourable or unfavourable in terms of resource supply. This no- 
tion of habitat heterogeneity, however, may be too simplistic, as under natural conditions, patches can be poor in one resource (e.g. light) and rich in another (e.g. water; Stuefer et al. 1994, 1996, Stuefer 1996, Holmgren et al. 1997, Hutchings and Wijesinghe 1997). High photon flux densities (PFD), for instance, tend to reduce plant water availability by creating high rates of evapo-transpiration (Young and Smith 1979, 1980, Schulze and Hall 1981, Larcher 1994).

It has been suggested that clonal plants may be able to exploit such environments on the basis of a "spatial division of labour" between interconnected ramets (Hutchings and de Kroon 1994, Stuefer et al. 1994, 1996, Alpert and Stuefer 1997, Stuefer 1998). This implies that interconnected ramets exchange different resources by bi-directional translocation, and that they specialize functionally in the uptake of the locally most abundant resource. Bi-directional translocation of assimilates and water can occur simultaneously between ramets, as these resources are translocated in the phloem and xylem, respectively (Qureshi and Spanner 1971, Marshall 1990).

The net effect of reciprocal resource transport between ramets on plant growth and biomass allocation combines the results of two different translocation processes, which are difficult to disentangle in experimental studies. Costs of assimilate export may be obscured by benefits of water import, and vice versa (Stuefer et al. 1994). Analytical tools for quantifying costs and benefits of resource translocation used by several authors (e.g. Salzman and Parker 1985, Slade and Hutchings 1987, Stuefer et al. 1994) are applicable to systems with uni-directional transport of resources only. They are not appropriate when two resources are simultaneously translocated in opposite directions (Stuefer and Hutchings 1994, Stuefer 1996).

In this study we used steam-girdling to disentangle and quantify the effects of reciprocal assimilate and water translocation between ramets of a clonal plant. Steam-girdling is a classical method from transport physiology which uses hot steam to locally disrupt phloem connections in stems, while leaving xylem vessels unaffected (Went 1923, Canny 1973, and see Stuefer 1995). Steam-girdling of stolon connection between ramets of a clonal plant allows to carry out separate cost-benefit analyses (sensu Salzman and Parker 1985) of bi-directional translocation of assimilates and water. In several pilot studies we tested whether steam-girdling effectively blocks assimilate transport through the stolon, without affecting water translocation. The main experiment was designed to quantify costs and benefits of resource exchange in clonal fragments. We subjected ramet pairs of the stoloniferous herb Potentilla anserina, with intact, steam-girdled or severed stolon connections, to heterogeneous, but complementary supplies of light and water.
The following hypotheses were tested in the main experiment: (1a) Biomass and clonal offspring production are positively related to the degree of integration between ramets. In other words, the productivity of ramet pairs is highest when the stolon connection is intact, intermediate when the stolon connection is steam-girdled (i.e. preventing assimilate translocation), and lowest when the stolon connection is severed (preventing assimilate and water translocation). (1b) The benefits of assimilate and water integration (i.e. the effects of resource import) exceed the costs of assimilate and water sharing (i.e. the effects of resource export) for both sides of the ramet pairs. (2) Integrated ramets specialize functionally (measured by root weight ratio) in the uptake of the locally most abundant resource, and non-integrated ramets specialize functionally in the uptake of the locally most limiting resource. Ramets of steam-girdled pairs are expected to show intermediate degrees of functional specialization.

\section{Material and methods}

\section{The species}

The stoloniferous, rosette-forming herb Potentilla anserina L. (Rosaceae) was used for all experiments. This species inhabits shores of lakes, rivers and the sea (Rousi 1965, Eriksson 1986b). Individual plants form long stolons from meristems in the axils of rosette leaves. Stolons grow sympodially (Wolf 1908) and they bear rooted or un-rooted ramets connected by stolon internodes. All stolon internodes wither in autumn, and formerly interconnected ramets become physically separated. Ramets pass the winter as short, thickened roots (Eriksson 1986b). For our experiments we took plants from a six-year-old stock population in the Botanical Gardens of Utrecht University, and pre-cultivated them on loamy sand in a plastic greenhouse (light transmission: $72 \%$ of full daylight).

\section{Steam-girdling and pilot studies}

Steam-girdling is a classical method to decouple phloem and xylem transport in plants (Went 1923, Canny 1973), which has recently been introduced to the study of clonal integration (Stuefer 1995). In our study, steam-girdling was locally (i.e. over a length of $1 \mathrm{~cm}$ ) applied to stolon internodes of $P$. anserina. Steamgirdling was carried out by using a steam generator constructed according to Canny (1973). To test the suitability of steam-girdling for the purpose of this study we carried out four pilot experiments described below. These tests were performed to investigate (1a) how long a stolon internode of $P$. anserina has to be steamed in order to disable assimilate transport 
through the phloem; (lb) whether regeneration of phloem occurs after steam-girdling, and whether steamgirdling affects (2a) short-term and (2b) long-term water transport between ramets.

(1a) We steam-girdled stolon internodes of $P$. anserina for $0,30,60$ or $90 \mathrm{~s}$. To assess the biological activity of the plant material, we incubated the treated pieces $(1 \mathrm{~cm})$ of stolon internode in a $0.5 \% 2,3,5$ triphenyltetrazolium chloride solution for $24 \mathrm{~h}$ at a temperature of $30^{\circ} \mathrm{C}$ (Larcher 1969, Towill and Mazur 1975). Microscopic inspection of the incubated stolon internodes revealed whether steam-girdling was effective in killing the phloem. Living cells are stained red, while dead tissue remains unstained.

(1b) The method described for pilot study la was used to determine whether phloem tissue regenerates after steam-girdling. Stolon internodes were steamed for $90 \mathrm{~s}$ and incubated after three weeks.

(2a) To investigate potential short-term effects of steam-girdling on water transport, we quantified rates of transpiration in two-ramet systems (Fig. 1). We prepared 21 ramet pairs by removing all rosette leaves from the developmentally older (i.e. "mother") ramet and by removing all roots from the developmentally younger (i.e. "daughter") ramet. Mother ramets were potted into sealed plastic boxes to ensure that water loss of ramet pairs can only occur through transpiration from leaves on the daughter ramets. Transpiration rates were measured by repeatedly weighing the ramet pairs and determining the weight loss of ramet pairs over periods of two hours. The stolon internodes of ten ramet pairs were steam-girdled for $90 \mathrm{~s}$, and the weight loss of all ramet pairs was measured again after two hours. We repeated this weighing procedure $18 \mathrm{~h}$ after the application of steam-girdling. The ratio between the weight loss before and after application of steamgirdling was calculated for each of the ramet pairs. This measure was used to test the assumption that steamgirdling does not affect transpiration rates.

(2b) To investigate long-term effects of steamgirdling on water transport, we prepared 24 ramet pairs, each consisting of a shaded, well-watered mother ramet and an unshaded, drought-stressed daughter

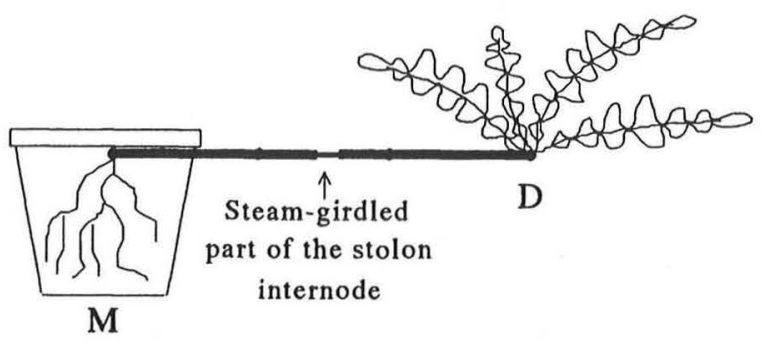

Fig. 1. Schematic illustration of a two-ramet system which was used to determine potential short-term effects of steamgirdling on water transport through the connecting stolon. $\mathrm{M}$ : mother ramet, D: daughter ramet.

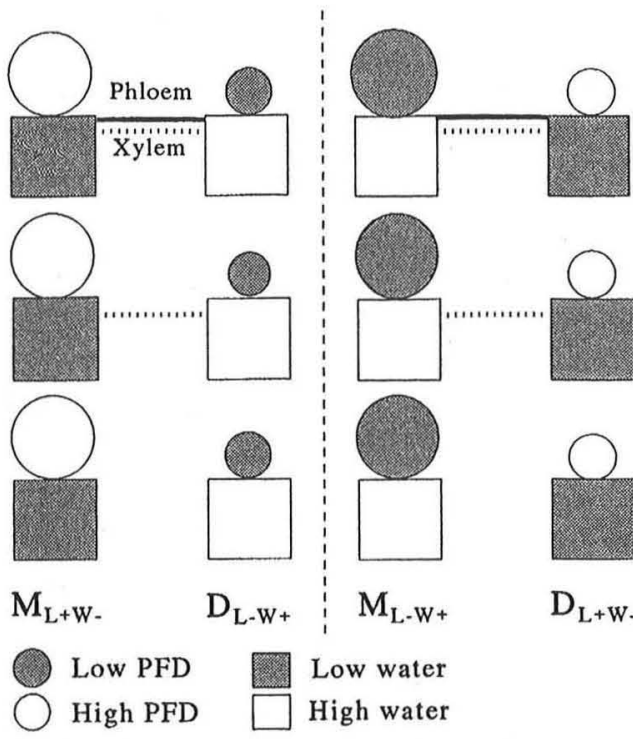

Fig. 2. Schematic representation of the six experimental treatments. Interconnected mother ramets $(\mathrm{M}$; large circles) and daughter ramets (D; small circles) were exposed to contrasting resource supplies. One ramet of each pair was exposed to high levels of PFD and low water supply $(\mathrm{L}+\mathrm{W}-)$, while the other was exposed to the complementary resource environment $(\mathrm{L}-\mathrm{W}+)$. Three integration treatments were imposed on the ramet pairs. I: intact stolon, S: steam-girdled stolon, C: cut stolon.

ramet (see right part of Fig. 2). We subjected each of these ramet pairs to one of three integration treatments (the same treatments as in the main experiment, see below): the stolon connection between the two ramets was left intact (I), steam-girdled (S) or cut (C). Nine days after the start of the experiment, mid-day leaf water potentials were measured on the youngest unfolded leaf of each daughter ramet.

\section{The experiment}

\section{Pre-cultivation of plants}

Mother ramets were grown individually in pots until they had formed a rooted daughter ramet on the third node of a stolon. We used ramets on the third node because a rather long stolon connection between mother and daughter ramets was required to place them into separate pots. We excavated the two connected ramets and planted them individually in round pots (diameter: $21 \mathrm{~cm}$; depth: $15 \mathrm{~cm}$ ) filled with loamy sand. The substrate was enriched with $12 \mathrm{~g}$ controlledrelease fertilizer (Osmocote Plus, Grace Sierra International, Heerlen, The Netherlands), which corresponds to a nitrogen release of $7.7 \mathrm{~g} \mathrm{~m}^{-3}$ week ${ }^{-1}$ (ca $20 \mathrm{~kg}$ $\mathrm{ha}^{-1}$ week ${ }^{-1}$ ). This nutrient regime was known to provide non-limiting nutrition for $P$. anserina (Stuefer unpubl.). At repotting, all leaves were removed from 
the first and second node (these nodes had no roots) and additional stolons were removed from the ramet pair. Mother and daughter ramets were standardized for size by reducing the number of leaves to five and two, respectively, and by cutting roots to a length of 14 $\mathrm{cm}$ and $12 \mathrm{~cm}$, respectively. To minimize carry-over effects on vegetative growth, storage roots were removed from mother ramets as far as possible. Daughter ramets had no storage roots.

\section{Experimental treatments}

At the start of the experiment (18 June 1996) we assigned 16 pre-cultivated ramet pairs to each of the three following integration treatments: 1 . the stolon connection between the two ramets was left intact (treatment I), 2. the stolon was steam-girdled for about $90 \mathrm{~s}$ with a steam generator (treatment S), 3. the stolon was cut (treatment C).

The ramet pairs were subjected to a spatially heterogeneous environment with a negative covariance between the availabilities of light and water (Fig. 2). One of the two ramets was grown under high PFD and low water supply (resource condition $\mathrm{L}+\mathrm{W}-$ ), while the connected ramet was grown under low PFD and high water supply (resource condition $\mathrm{L}-\mathrm{W}+$ ). For half of the ramet pairs (i.e. 24 out of a total of 48 ramet pairs) the mother ramet was exposed to $\mathrm{L}+\mathrm{W}-$ and the daughter ramet to $\mathrm{L}-\mathrm{W}+\left(\mathrm{M}_{\mathrm{L}+\mathrm{W}}-\mathrm{D}_{\mathrm{L}-\mathrm{w}+}\right.$, left part in Fig. 2), while for the rest of the ramet pairs the mother ramet was exposed to $\mathrm{L}-\mathrm{W}+$ and the daugh-

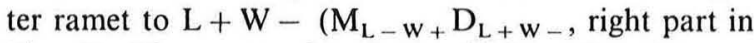
Fig. 2). These two situations will be referred to as positioning treatments. We randomly distributed the replicates over two shade cages in the greenhouse according to a randomized block design.

Ramets in the $\mathrm{L}-\mathrm{W}+$ environment received $20 \%$ of ambient daylight (PFD) in the greenhouse, and their water supply was adjusted daily to $80 \%$ of field capacity (FC). Shading was imposed by shade cages covered with spectrally neutral shade cloth. Ramets in the $\mathrm{L}+$ W - environment were positioned outside, but close to, the shade cages. As a consequence, these plants received $80 \%$ (instead of $100 \%$ ) of ambient daylight in the greenhouse. The water content of pots was monitored daily with a frequency domain (FD) meter which had been pre-calibrated for the substrate used in the experiment (Hilhorst et al. 1992, Dirksen and Hilhorst 1994, Hilhorst and Dirksen 1994). If the water content in $\mathrm{L}+\mathrm{W}$ - pots was lower than $30 \% \mathrm{FC}$, pots were replenished with tap water to $30 \% \mathrm{FC}$. A previous study had shown that a water availability of $30 \%$ FC causes strong but non-lethal drought-stress to ramets of $P$. anserina (van Kleunen unpubl.).

All plants were harvested three weeks after the start of the experiment. Each mother and daughter ramet (including secondary stolons formed by these ramets during the experiment) was subdivided into roots, living leaves, dead leaves, stolon internodes, and inflorescences. Plant parts were weighed separately after drying them to constant mass at $70^{\circ} \mathrm{C}$. The number of secondary ramets formed during the experiment was counted for each ramet. The area and dry mass of the youngest unfolded leaf of each mother and daughter ramet were measured after cutting out the rachis. These data were used to estimate the specific leaf area (SLA). The root weight ratio (RWR) was calculated for each mother and daughter ramet by dividing the total belowground biomass by the total biomass. Root-weight ratios were preferred to root-shoot ratios in this study because they show a linear relation to root allocation (and shoot allocation), while root-shoot ratios do not.

\section{Cost-benefit analyses}

Cost-benefit analyses were performed to quantify the effects of assimilate and water integration in the two ramet systems. Costs and benefits were calculated separately for mother (M) and for daughter (D) ramets, and we used biomass and secondary ramet (i.e. clonal offspring) production as currencies of plant growth and performance. The costs of assimilate translocation (for either $\mathrm{M}$ or $\mathrm{D})$ were calculated as difference in biomass and secondary ramet production between the assimilate exporting part in the control treatment (I) and the corresponding ramet $(\mathrm{M}$ or $\mathrm{D})$ in the steam-girdling treatment (S; see Fig. 3). The benefits of assimilate translocation were calculated as difference in biomass and secondary ramet production between the assimilate importing part in the control treatment and the corresponding part ( $\mathrm{M}$ or $\mathrm{D})$ in the steam-girdling treatment (Fig. 3). The costs and benefits of water translocation were calculated in an analogous way. They were defined as differences in biomass and secondary ramet production between water exporting and water importing parts (M or $\mathrm{D})$ in the steam-girdling treatment (S) and the corresponding ramet in the severing treatment $(\mathrm{C}$; Fig. 3).

\section{Statistical analyses}

Analysis of variance (type III sum of squares) was used to analyse the effects of integration treatments on variables referring to entire ramet pairs as well as to individual mother and daughter ramets. Integration treatments (I, S and C) were considered fixed effects. The two shade cages were treated as a fixed block effect with replication (see Potvin 1993). Variables referring to entire ramet pairs were analysed separately for the

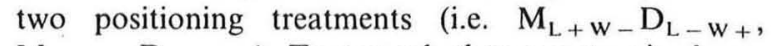
$\mathrm{M}_{\mathrm{L}-\mathrm{w}_{+}} \mathrm{D}_{\mathrm{L}+\mathrm{w}_{-}}$). To test whether ramet pairs benefited from the translocation of assimilates and water, contrasts were performed to compare treatments I versus $S$ 
(testing for assimilate integration effects), and $\mathrm{S}$ versus $C$ (testing for water translocation effects).

Variables referring to individual ramets ( $M$ or $D)$ were analysed separately for $M$ and $D$ in each of the two resource environments (i.e. $\mathrm{L}+\mathrm{W}-$ and $\mathrm{L}-\mathrm{W}+$ ). We used linear contrasts to test for effects of assimilate and water transport. For ramets in $\mathrm{L}+\mathrm{W}-$, linear contrasts were performed between treatments I \& S versus $\mathrm{C}$, and between I versus $\mathrm{S}$. The first of these contrasts tests for effects of water import, which was possible in $\mathrm{I}$ and $\mathrm{S}$, but not in $\mathrm{C}$. The second contrast tests for effects of assimilate export. For ramets in $\mathrm{L}-\mathrm{W}+$, linear contrasts were performed between treatments I versus $\mathrm{S} \& \mathrm{C}$, and between $\mathrm{S}$ versus $\mathrm{C}$. The
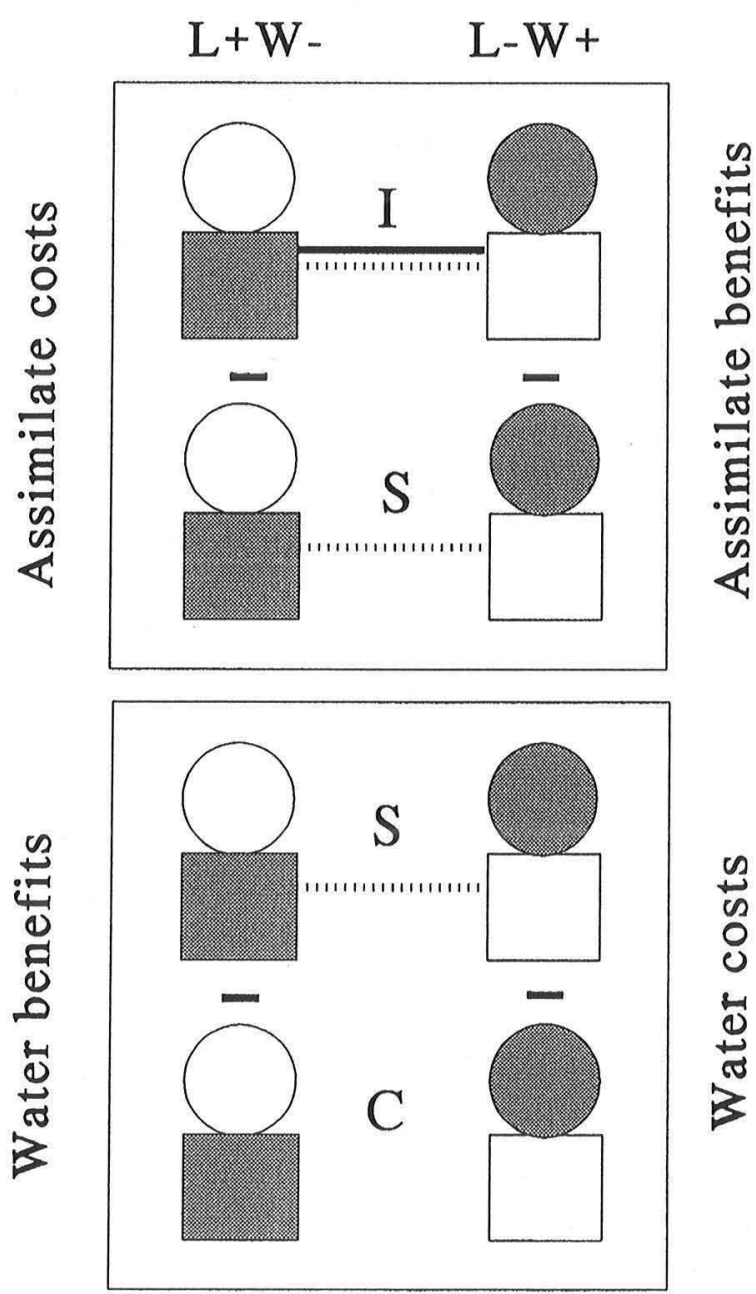

Fig. 3. Graphical representation of the definition of costs and benefits of assimilate (upper part) and water (lower part) translocation. Costs and benefits of resource translocation are calculated by subtracting trait values (biomass, numbers of secondary ramets) of the ramet below the minus $(-)$ symbol from the value of the ramet above this symbol. Note that costs of resource translocation are represented by negative values. $\mathrm{L}+\mathrm{W}-$ : high PFD/low water supply; L - W + : low PFD/ high water supply. I: intact stolon; S: steam-girdled stolon; $\mathrm{C}$ : cut stolon. first of these contrasts tests for effects of assimilate import, which was possible in I, but not in S and C. The second contrast tests for effects of water export.

To test whether the costs and benefits of assimilate and water translocation were significantly different from zero, we used non-orthogonal contrasts comparing treatments I versus $S$ (costs and benefits of assimilate translocation, see Fig. 3 ), and $S$ versus $C$ (costs and benefits of water translocation, see Fig. 3). For all analyses which included non-orthogonal comparisons, significance levels were adjusted according to the Bonferroni method (Sokal and Rohlf 1995).

\section{Results}

\section{Pilot studies}

Pilot experiment (la) has shown that steam-girdling effectively destroys all phloem cells, and thus blocks assimilate transport, in stolon internodes of $P$. anserina within $90 \mathrm{~s}$. Pilot experiment (1b) has revealed that no phloem regeneration occurs within three weeks after steam-girdling in stolon internodes of $P$. anserina. No living cells were found in the treated internode section after this period of time. Pilot experiment (2a) showed that steam-girdling had a slight effect on short-term water transport in the ramet pairs. The ratio between transpiration rates before and immediately after steamgirdling was $5 \%$ lower $\left(F_{1,19}=9.5 ; p<0.01\right)$ for steamgirdled than for intact ramet pairs. Eighteen hours after steam-girdling, this difference was $16 \%\left(F_{1.19}=45.0\right.$; $p<0.001$ ). Pilot experiment (2b) showed that steamgirdling does not affect water relations in the longer term. Nine days after application of steam-girdling, there was no effect of this treatment on leaf water potentials (treatment I: $-1.73 \pm 0.07 \mathrm{MPa}$; treatment $\mathrm{S}:-1.77 \pm 0.03 \mathrm{MPa}$; contrast I vs $\mathrm{S}: F_{1,21}=0.4$; $p>0.05$ ). Severing stolon connections considerably decreased leaf water potentials of unshaded, droughtstressed ramets (treatment $\mathrm{C}$ : $-2.63 \pm 0.10 \mathrm{MPa}$; contrast I \& S vs C: $\left.F_{1,21}=99.6 ; p<0.001\right)$.

\section{Main experiment}

\section{Biomass and clonal offspring production}

Total biomass and clonal offspring (secondary ramet) production of ramet pairs was highest in the control treatment (I), intermediate in the steam-girdling treatment $(\mathrm{S})$, and lowest in the severing treatment $(\mathrm{C}$; Table 1). This was true for both positioning treatments $\left(M_{L+w_{-}} D_{L-W_{+}}, M_{L-W_{+}} D_{L+w_{-}}\right)$. The effects of assimilate integration were not statistically significant on the whole plant basis, while the effects of water integration were (Table 2). 
Table 1. Effects of integration treatments (a) on the mean ( $\pm 1 \mathrm{SE}$ ) total dry weight $[\mathrm{g}]$, and $(\mathrm{b})$ number of secondary ramets produced by entire ramet pairs. M: mother ramet; $\mathrm{D}$ : daughter ramet. $\mathrm{L}+\mathrm{W}-$ : high $\mathrm{PFD} /$ low water supply; $\mathrm{L}-$ $\mathrm{W}+$ : low PFD/high water supply. I: intact stolon, S: steamgirdled stolon; C: cut stolon.

\begin{tabular}{llll}
\hline Ramet pair & \multicolumn{3}{l}{ Integration treatment } \\
\cline { 2 - 4 } & $\mathrm{I}$ & $\mathrm{S}$ & $\mathrm{C}$ \\
\hline (a) & & & \\
$\mathrm{M}_{\mathrm{L}+\mathrm{W}-\mathrm{D}_{\mathrm{L}-\mathrm{W}+}}$ & $7.71 \pm 0.39$ & $6.75 \pm 0.30$ & $4.43 \pm 0.22$ \\
$\mathrm{M}_{\mathrm{L}-\mathrm{W}+} \mathrm{D}_{\mathrm{L}+\mathrm{W}-}$ & $7.63 \pm 0.29$ & $6.65 \pm 0.46$ & $5.01 \pm 0.26$ \\
(b) & & & \\
$\mathrm{M}_{\mathrm{L}+\mathrm{W}-\mathrm{D}_{\mathrm{L}-\mathrm{W}+}} 20.5 \pm 2.0$ & $16.8 \pm 1.5$ & $10.6 \pm 1.0$ \\
$\mathrm{M}_{\mathrm{L}-\mathrm{W}+} \mathrm{D}_{\mathrm{L}+\mathrm{W}-}$ & $19.3 \pm 1.5$ & $17.0 \pm 0.8$ & $12.0 \pm 1.3$ \\
\hline
\end{tabular}

The biomass and secondary ramet production (Fig. $4 \mathrm{a}, \mathrm{b})$ of unshaded, drought-stressed mother or daugh-

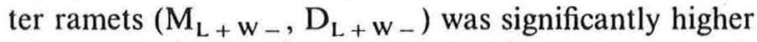
when water import from a connected ramet was possible (treatments I, S) rather than disabled (treatment C; Table 3). The dry weight and number of secondary ramets of shaded, well-watered ramets $\left(\mathrm{M}_{\mathrm{L}-\mathrm{w}+}\right.$, $\mathrm{D}_{\mathrm{L}-\mathrm{W}_{+}}$) was lower when assimilate import was disabled (treatments $\mathrm{S}, \mathrm{C}$ ) than when stolon connections between ramets remained intact (treatment I; Fig. 4a, b). This effect was statistically significant for daughter ramets but not for mother ramets (Table 3 ). Biomass and clonal offspring production of daughter ramets $\left(D_{L-}-w_{+}\right)$was significantly lower when the stolon connection was steam-girdled rather than severed (Fig. 4a, b, Table 3). This effect (i.e. costs of water export) was absent for mother ramets in the same environment $\left(M_{L-w_{+}}\right.$; see Fig. 4a, b, Table 3).

\section{Root weight ratio}

The root weight ratio (RWR) of unshaded, droughtstressed ramets $\left(M_{L_{+} W_{-}}, D_{L_{+} W_{-}}\right)$was lowest when stolon connections were left intact (I), intermediate when they were steam-girdled (S), and highest when severed (C; Fig. 4c). The effect of manipulating assimilate integration on RWR was statistically significant for mother ramets only (Table 3), while the effect of water integration was significant for mother and for daughter ramets (Table 3 )
The RWR of shaded, well-watered daughter ramets was significantly affected by integration treatments. This effect was absent from mother ramets in this environment. For daughter ramets the RWR was lowest when the stolon connection was severed (C), intermediate when it was left intact (I), and highest when it was steam-girdled (S). The effect of assimilate integration was not statistically significant (Table 3 ), while the effect of water integration was (Table 3 ).

\section{Specific leaf area}

The specific leaf area (SLA) of unshaded, drought-

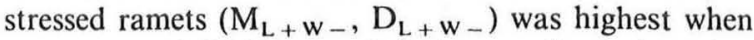
ramets were fully integrated (I), intermediate when they were steam-girdled $(S)$, and lowest when they were severed (C; Fig. 4d). Assimilate and water integration had statistically significant effects on the specific leaf area (Table 3).

The SLA of shaded, well-watered mother ramets $\left(\mathrm{M}_{\mathrm{L}-\mathrm{W}_{+}}\right)$was not significantly affected by integration treatments (Table 3). The SLA of shaded, well-watered daughter ramets $\left(D_{L_{-} w_{+}}\right)$was highest when ramets were disconnected $(C)$, intermediate when they were steam-girdled (S), and lowest when they were fully integrated (I; Fig. 4d). Only the effect of assimilate integration was statistically significant (Table 3 ).

\section{Cost-benefit analyses}

The benefits of assimilate and of water import were high for ramet pairs with unshaded, drought-stressed mother ramets $\left(\mathrm{M}_{\mathbf{L}+\mathrm{W}_{-}}\right)$connected to shaded, wellwatered daughter ramets $\left(\mathrm{D}_{\mathrm{L}_{-} \mathrm{w}_{+}}\right.$; Fig. $\left.5 \mathrm{~b}, \mathrm{c}\right)$. The costs of resource export were generally small in these ramet pairs, and only statistically significant for water export in terms of secondary ramet production (Table 4).

No statistically significant benefits and costs of assimilate translocation were found for ramet pairs with shaded, well-watered mother ramets $\left(\mathrm{M}_{\mathrm{L}_{-}-\mathrm{w}_{+}}\right)$connected to unshaded, drought-stressed daughter ramets

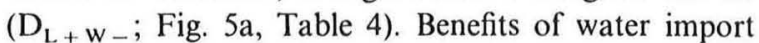
were statistically significant. There were no significant costs of water export in these ramet pairs (Fig. 5d, Table 4).

Table 2. Results of analyses of variance, testing effects of integration treatments on production parameters of entire ramet pairs. The upper part of the table refers to ramet pairs with an unshaded, drought-stressed mother ramet and a shaded, well-watered daughter ramet $\left(\mathrm{M}_{\mathrm{L}+\mathrm{W}_{-}} \mathrm{D}_{\mathrm{L}_{-} \mathrm{W}_{+}}\right)$. The lower part refers to ramet pairs with a shaded, well-watered mother ramet and an unshaded, drought-stressed daughter ramet $\left(\mathrm{M}_{L_{-} \mathrm{w}_{+}} \mathrm{D}_{L_{+}} \mathrm{w}_{-}\right)$. The table gives the results of two non-orthogonal contrasts comparing the effects of different integration treatments. $*: p<0.05 ; * *: p<0.01 ; * * *: p<0.001$.

\begin{tabular}{lccc}
\hline Variable & $\begin{array}{c}F_{\text {integration }} \\
\mathrm{df}=2,18\end{array}$ & $F_{\text {assimilate contrast }}$ & $F_{\text {water contrast }}$ \\
\hline$M_{L+W-D_{L-W+}}$ & & & $25.65^{* * *}$ \\
Total dry weight & $27.04^{* * *}$ & 2.35 & $7.11^{* * *}$ \\
No. secondary ramets & $9.42^{* *}$ & & $10.67^{* *}$ \\
$M_{L-W+} D_{L+W-}$ & & 3.79 & $8.63^{*}$ \\
Total dry weight & $13.88^{* * *}$ & 1.75 & \\
No. secondary ramets & $9.51^{* *}$ & & \\
\hline
\end{tabular}


a)

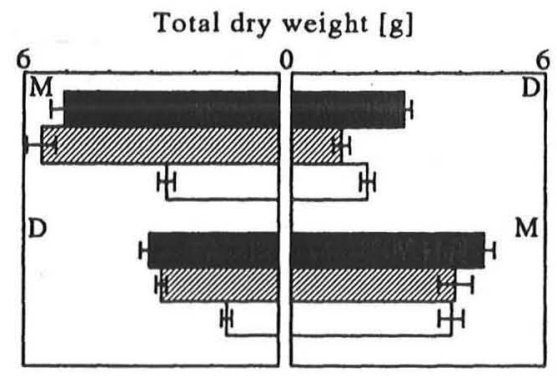

b)

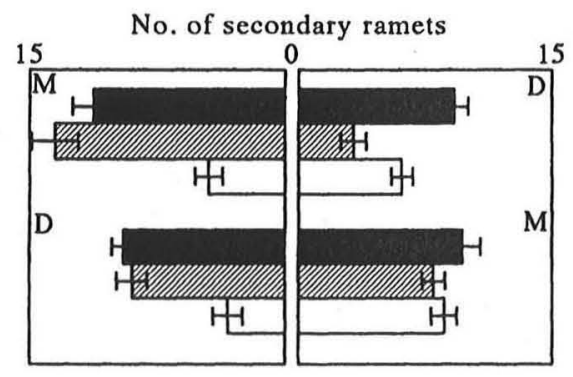

c)

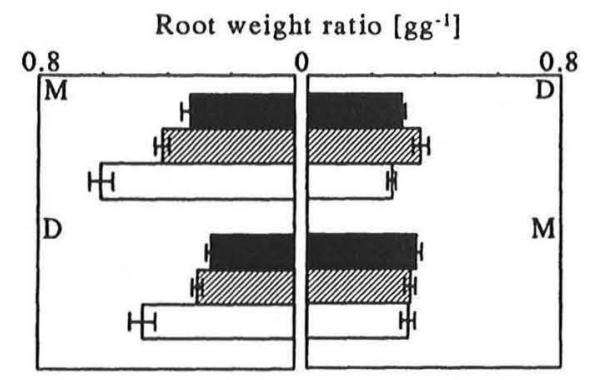

d)

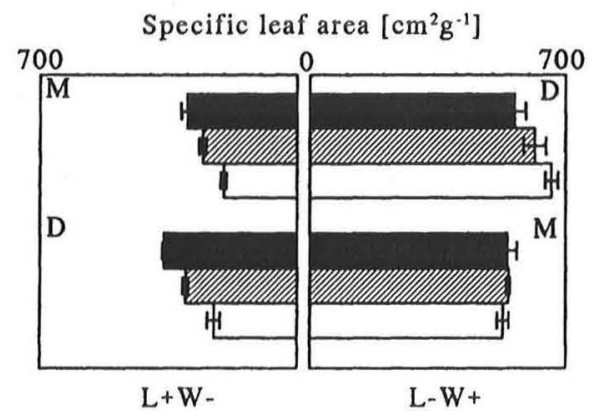

Fig. 4. Mean ( \pm 1 SE) values for a) dry weight, b) number of secondary ramets, c) root weight ratio and d) specific leaf area for mother (M) and daughter (D) ramets with intact (black bars, I), steam-girdled (hatched bars, S) or cut (open bars, C) stolons. The ramets were unshaded and drought-stressed $(\mathrm{L}+$ $\mathrm{W}-$ ) or shaded and well-watered $(\mathrm{L}-\mathrm{W}+)$.

\section{Discussion}

Specific disruption of assimilate transport between connected ramets by the use of steam-girdling proved an effective method to disentangle and to quantify the effects of assimilate and water integration in clonal plants. Our results provide evidence that interconnected ramets of $P$. anserina can benefit from bi-directional translocation of two different resources (water and assimilates), and that these benefits are related to the degree and to the mode of physiological integration within clonal fragments. The results of this study furthermore show that the degree of structural and functional specialization of ramets in the uptake of locally abundant resources (Friedman and Alpert 1991, Stuefer et al. 1994, 1996), depends on both local and non-local supply and demand of the two translocated resources.

\section{Steam-girdling}

Our results have shown that steam-girdling is a suitable method for investigating the effects of resource transport in clonal plants. Our data have shown that steam-girdling effectively blocks assimilate translocation through stolon internodes of $P$. anserina by locally destroying the phloem tissue (see Bennett et al. 1984, Grignon et al. 1989). Phloem regeneration (Kollmann and Schulz 1993) during long-term experiments can be considered unlikely if the stolon is steamed over a distance of $10 \mathrm{~mm}$ or more. Our pilot study (lb) has confirmed this prediction by showing that no living phloem tissue was present at the treated internode segments three weeks after steam-girdling.

Our pilot studies have shown that steam-girdling can have short-term effects on water transport. However, there was no sign of long-term effects of steamgirdling on water transport through stolons. Water translocation, measured as rates of transpiration from a root-less ramet that was connected to a rooted, leaf-less ramet (Fig. 1), decreased slightly after steamgirdling (see also Stock and Silvester 1994). Reduced rates of transpiration which are recorded shortly after steam-girdling do not necessarily result from direct effects of steam-girdling on the water conductivity of xylem vessels, but they can be a consequence of temporary sink-limitation. In our ramet pairs, steamgirdling disconnected the transpiring leaves from a strong assimilate sink (i.e. roots of the connected, leafless ramet) which is likely to result in a transient closure of the stomata (King et al. 1967, Lenz and Williams 1973) and thus in a decrease of the rate of transpiration. In the long term ( 9 d) the leaf water potential of drought-stressed ramets was not affected by steam-girdling, which indicates that steam-girdling did not impair the water conductivity of xylem vessels. We hence conclude that steam-girdling is a suitable method to separate the effects of assimilate and water translocation in clonal plants. 


\section{Costs and benefits of bi-directional resource translocation}

Our study expands the classical analysis of costs and benefits of uni-directional translocation of resources in clonal plants to bi-directional transport processes. The definition of costs and benefits of physiological integration given by Salzman and Parker (1985) implies that interconnected clone parts can unequivocally be designated as source or as sink sites, and that ramets can not simultaneously import and export different resources (Salzman and Parker 1985, Stuefer and Hutchings 1994, Stuefer et al. 1994, Stuefer 1996). Applying such a cost-benefit analysis to clonal plants exposed to heterogeneous environments with complementary resource supplies can yield unexpected results such as negative cost terms (Stuefer et al. 1994), because the benefits of importing one resource (e.g. water) can outweigh or override the costs of exporting another resource (e.g. assimilates). As a consequence, costs and benefits cannot be quantified separately if exchange of different resource occurs between interconnected ramets. We used the technique of steam-girdling to overcome this problem and to extend the original definition of costs and benefits of clonal integration to reciprocal resource transport between ramets.

Plant performance (i.e. total biomass and secondary ramet production) was highest when ramet pairs were fully integrated, intermediate when assimilate transport was disrupted by steam-girdling, and lowest when ramets were severed. This confirms our hypothesis that the degree of clonal integration is positively related to plant growth and performance. Benefits of resource import were (in most cases) large and highly significant. This was true for both assimilates and water. Costs of resource export, on the other hand, tended to be small and (in most cases) not statistically significant (Fig. 5,
Table 4). These findings confirm the notion expressed by various authors that clonal plants can significantly profit from a spatial complementarity of different resources (Lau and Young 1988, Friedman and Alpert 1991, Hutchings and de Kroon 1994, Stuefer et al. 1994, 1996, 1998, Stuefer 1995, 1998, Alpert and Stuefer 1997, Hutchings and Wijesinghe 1997). In addition, our data provide experimental evidence that these benefits are due to the combined effects of assimilate and of water transport between connected ramets.

Costs of resource export were generally small and often non-significant in our study. This is in agreement with earlier findings (Slade and Hutchings 1987, Evans and Whitney 1992, Peterson 1996) and suggests that resource export from donor ramets is either restricted to surplus resources or that the rate of uptake is enhanced by an increased, non-local demand for this resource (Hartnett and Bazzaz 1983, Pitelka and Ashmun 1985, Marshall 1990). In the present study only shaded, well-watered daughter ramets $\left(D_{L-w_{+}}\right)$incurred significant costs of resource export. In this case water transport to connected ramets $\left(\mathrm{M}_{\left.\mathrm{L}_{-} \mathrm{w}_{+}\right)}\right)$had a negative effect on clonal offspring production (Table 4). However, these costs were more than outweighed by benefits of assimilate import by these ramets, resulting in a positive overall balance of costs and benefits of resource sharing. Significant costs of water export in clonal plants have previously been reported for $\mathrm{Am}$ brosia psilostachya spanning a gradient in soil salinity (Salzman and Parker 1985), and for Carex flacca spanning a gradient in water availability (de Kroon et al. 1996).

Mother ramets which were exposed to shaded, wellwatered conditions $\left(\mathrm{M}_{\mathrm{L}-\mathrm{w}_{+}}\right)$did not benefit from assimilate sharing with unshaded, drought-stressed daughter ramets $\left(D_{L+W_{-}}\right)$. This result suggests that basipetal assimilate transport did either not occur in

Table 3. Results of statistical tests of the effects of integration treatments on production and allocation parameters of mother and daughter ramets exposed to two different resource environments $(\mathrm{L}+\mathrm{W}-$, left-hand part of table; $\mathrm{L}-\mathrm{W}+$, right-hand part of table). The table gives the results of two orthogonal contrasts comparing the effects of different integration treatments. *: $p<0.05 ; * *: p<0.01 ; * * *: p<0.001$.

\begin{tabular}{|c|c|c|c|c|c|c|}
\hline \multirow{3}{*}{$\begin{array}{l}\text { (a) } \\
\text { Variable }\end{array}$} & \multicolumn{3}{|c|}{ high PFD/low water $(\mathrm{L}+\mathrm{W}-)$} & \multicolumn{3}{|c|}{ low PFD/high water $(\mathrm{L}-\mathrm{W}+)$} \\
\hline & \multicolumn{3}{|l|}{ Mother } & \multicolumn{3}{|l|}{ Daughter } \\
\hline & $\begin{array}{l}F_{\text {integration }} \\
\mathrm{df}=2,18^{\#}\end{array}$ & $F_{\text {assimilate contrast }}$ & $F_{\text {water contrast }}$ & $\begin{array}{l}F_{\text {integration }} \\
\mathrm{df}=2,18\end{array}$ & $F_{\text {assimilate contrast }}$ & $F_{\text {water contrast }}$ \\
\hline Total dry weight & $40.73 * * *$ & 2.37 & $79.09^{* * *}$ & $17.27 * * *$ & $28.63 * * *$ & $5.91 *$ \\
\hline No. secondary ramets & $16.04 * * *$ & 1.85 & $30.22 * * *$ & $17.12 * * *$ & $26.38 * * *$ & $7.86^{*}$ \\
\hline Root weight ratio & $25.64 * * *$ & $4.71 *$ & $46.58 * * *$ & $8.01^{* *}$ & 0.42 & $15.61 * * *$ \\
\hline Specific leaf area & $15.49 * * *$ & $6.38^{*}$ & $24.60^{* * *}$ & 3.35 & $5.37^{*}$ & 1.32 \\
\hline (b) & \multicolumn{3}{|l|}{ Daughter } & \multicolumn{3}{|l|}{ Mother } \\
\hline Total dry weight & $48.73 * * *$ & 2.07 & $95.40 * * *$ & 1.87 & 3.68 & 0.05 \\
\hline No. secondary ramets & $21.70 * * *$ & 0.23 & $43.17 * * *$ & 0.96 & 1.68 & 0.24 \\
\hline Root weight ratio & $26.84^{* * *}$ & 1.86 & $51.82 * * *$ & 0.49 & 0.92 & 0.07 \\
\hline Specific leaf area & $51.36 * * *$ & $19.65 * * *$ & $83.08 * * *$ & 0.37 & 0.16 & 0.58 \\
\hline
\end{tabular}

\# Denominator df of specific leaf area is 17. 
Fig. 5. Costs and benefits (black area) of simultaneous, bi-directional translocation of assimilates $(\mathrm{a}, \mathrm{b})$ and water $(c, d)$, for mother $(M)$ and for daughter ramets (D) in terms of biomass production Abbreviations as in Fig. 3. ***: $p<0.001$ a)

$$
\mathrm{M}_{\mathrm{L}-\mathrm{W}+} \quad \mathrm{D}_{\mathrm{L}+\mathrm{W}-}
$$

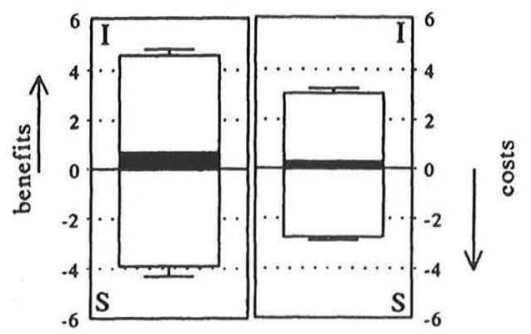

c)

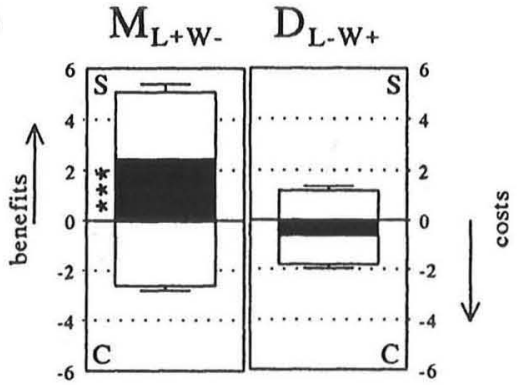

b) $\mathrm{D}_{\mathrm{L}-\mathrm{W}+} \quad \mathrm{M}_{\mathrm{L}+\mathrm{W}-}$

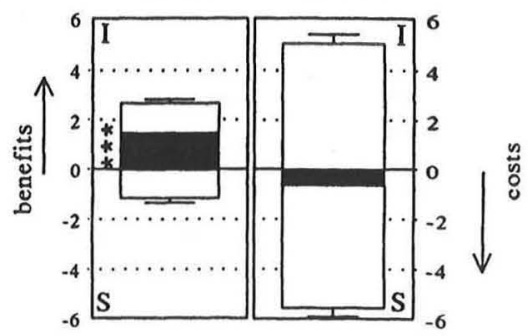

d)

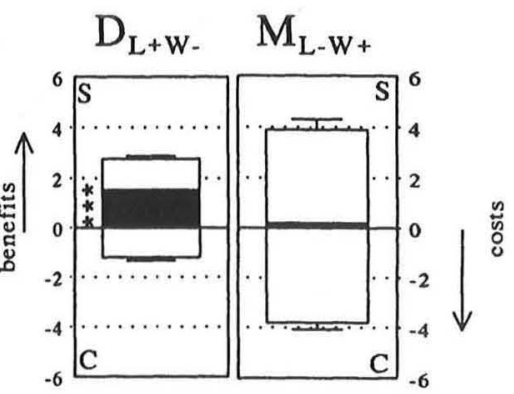

our experimental systems, or did not result in significant growth responses. This is in agreement with earlier findings for $P$. anserina (Stuefer et al. 1994). The absence of significant benefits of assimilate translocation from daughter to mother ramets is in agreement with mathematical models which predict that assimilate export from small daughter to large mother ramets is unlikely to occur (Eriksson and Jerling 1990, Caraco and Kelly 1991). The beneficial effect (on mother ramets) of importing a certain amount of assimilates may be smaller than the negative effect (on daughters) of exporting the same amount of resources, leading to a negative balance of costs and benefits of assimilate transport on the performance of clonal fragments.

The balance between costs and benefits of reciprocal resource translocation was positive in all cases of our experiment. This strongly suggests that integrated ramet pairs of $P$. anserina can effectively exploit heterogeneous environments with complementary availabilities of resources on the basis of bi-directional translocation of assimilates and water between interconnected ramets.

\section{Clonal integration and functional specialization}

Our study has shown that interconnected ramets of $P$. anserina can specialize functionally in the uptake of a locally abundant resource. The root weight ratio of unshaded, drought-stressed ramets was significantly lower when connected to a ramet in the complementary patch type than when the connection was severed. Our data furthermore show that the root weight ratio of unshaded, drought-stressed $(\mathrm{L}+\mathrm{W}-)$ ramets was intermediate in the steam-girdling treatment. This indicates that patterns of root-shoot allocation and functional specialization of ramets are affected by both the (non-local) supply of water and by the (non-local) demand for assimilates by connected ramets.

Functional specialization of ramets for the uptake of different resources is only feasible if ramets exchange captured resources. Specialization may greatly enhance the beneficial effects of bi-directional resource transport as it increases the efficiency of resource extraction from a heterogeneous environment (Stuefer et al. 1994, 1996, 1998, Alpert and Stuefer 1997, Hutchings and Wijesinghe 1997, Stuefer 1998). It is still unclear, however, to which degree specialization contributes to the benefits of a division of labour in clonal plants. Mathematical modelling may help to solve this issue (Stuefer

Table 4. Costs and benefits of simultaneous, bi-directional translocation of assimilates and water in terms of number of secondary ramets produced during the experiment. Abbreviations as in Table 1. Note that costs are given as negative values.

\begin{tabular}{lllll}
\hline Resource & Benefits & Costs & Benefits & Costs \\
\hline \multirow{2}{*}{ Water } & $\frac{\mathrm{M}_{\mathrm{L}+\mathrm{W}-}}{9.00^{* * *}}$ & $\frac{\mathrm{D}_{\mathrm{L}-\mathrm{W}+}}{-2.88^{*}}$ & $\frac{\mathrm{D}_{\mathrm{L}+\mathrm{W}-}}{5.62^{* * *}}$ & $\frac{\mathrm{M}_{\mathrm{L}-\mathrm{W}+}}{-0.63}$ \\
\cline { 2 - 3 } Assimilates & $\frac{\mathrm{M}_{\mathrm{L}-\mathrm{W}+}}{1.75}$ & $\frac{\mathrm{D}_{\mathrm{L}+\mathrm{W}}}{0.50}$ & $\frac{\mathrm{D}_{\mathrm{L}-\mathrm{W}+}}{6.00^{* *}}$ & $\frac{\mathrm{M}_{\mathrm{L}+\mathrm{W}-}}{-2.25}$ \\
\hline
\end{tabular}


et al. 1998). Our study also revealed non-local effects on the specific leaf area (SLA) of ramets. This was especially pronounced when ramets were unshaded and drought-stressed. Similar effects were reported by other authors (Slade and Hutchings 1987, Friedman and Alpert 1991, Evans 1992), but the proximate mechanism for plasticity in biomass allocation, as well as potential ultimate consequences of these responses remain unclear.

The costs of water export incurred by shaded, wellwatered daughter ramets may be a consequence of the high degree of functional specialization of these ramets in the steam-girdling treatment in comparison with ramets in the severing treatment (see Fig. 4c). The high water demand of the connected mother ramets may have forced the daughter ramets in the steam-girdling treatment to invest a relatively large proportion of biomass in roots instead of leaves. The relatively small assimilate production potential (i.e. leaves) of ramets in the steam-girdling treatment resulted in less biomass, although this effect was statistically not significant in the cost-benefit analysis, and less clonal offspring production than in severed ramets. In intact clonal systems such costs of water integration may be obscured by benefits of assimilate import from connected mother ramets.

The use of steam-girdling has enabled us to perform separate cost-benefit analyses for the bi-directional translocation of two different resources. This method could further serve as a powerful tool to investigate effects of non-local resource supply in clonal plants.

Acknowledgements - We thank Patrick Lansing and Jojanneke Meloen for practical assistance, and Heinjo During, Markus Fischer, Mike Hutchings and Tsvi Sachs for comments on earlier drafts of the manuscript. This manuscript was prepared during a stay of JFS at Hokkaido University (Japan), funded by the Goho Life Science International Fund.

\section{References}

Alpert, P. and Stuefer, J. F. 1997. Division of labour in clona plants: on the economy and ecology of specialization and cooperation among interconnected ramets. - In: de Kroon, H. and van Groenendael, J. (eds), The ecology and evolution of clonal plants. Backhuys, Leiden, pp. 137-154.

Bennett, A. B., Sweger, B. L. and Spanswick, R. M. 1984. Sink to source translocation in soybean. - Plant Physiol 74: $434-436$.

Canny, M. J. 1973. Phloem translocation. - Cambridge Univ. Press, Cambridge.

Caraco, T. and Kelly, C. K. 1991. On the adaptive value of physiological integration in clonal plants. - Ecology 72 : 81-93.

de Kroon, H., Fransen, B., van Rheenen, J. W. A., van Dijk, A. and Kreulen, R. 1996. High levels of inter-ramet water translocation in two rhizomatous Carex species, as quantified by deuterium labelling. - Oecologia 106: 73-84

Dirksen, C. and Hilhorst, M. A. 1994. Calibration of a new frequency domain sensor for soil water content and bulk electrical conductivity. - In: Proceedings of a symposium on TDR in environmental, infrastructure and mining applications. Evanston, IL, pp. 143-153.
Eriksson, O. 1986a. Mobility and space capture in the stoloniferous plant Potentilla anserina. - Oikos 46: 82-87.

Eriksson, O. 1986b. Survivorship, reproduction and dynamics of ramets of Potentilla anserina on a Baltic seashore meadow. - Vegetatio 67: 17-25.

Eriksson, O. and Jerling, L. 1990. Hierarchical selection and riskspreading in clonal plants. - In: van Groenendael, J. and de Kroon, H. (eds), Clonal growth in plants: regulation and function. SPB Acad. Publ., The Hague, pp. 79-94.

Evans, J. P. 1992. The effect of resource availability and clonal integration on ramet functional morphology in Hydrocotyle bonariensis. - Oecologia 89: 265-276.

Evans, J. P. and Whitney, S. 1992. Clonal integration across a salt gradient by a non-halophyte, Hydrocotyle bonariensis (Apiaceae). - Am. J. Bot. 79: 1344-1347.

Friedman, D. and Alpert, P. 1991. Reciprocal transport between ramets increases growth of Fragaria chiloensis when light and nitrogen occur in separate patches but only if patches are rich. - Oecologia 86: 76-80.

Grignon, N., Touraine, B. and Durand, M. 1989. 6(5)carboxy fluorescein as a tracer of phloem sap translocation. - Am. J. Bot. 76: 871-877.

Hartnett, D. C. and Bazzaz, F. A. 1983. Physiological integration among intra clonal ramets in Solidago canadensis. Ecology 64: 779-788.

Hilhorst, M. A and Dirksen, D. 1994. Dielectric water content sensors: time domain versus frequency domain. - In: Proceedings of a symposium on TDR in environmental, infrastructure and mining applications. Evanston, IL, pp. 23-33.

Hilhorst, M. A., Groenwold, J. and Groot, J. F. 1992. Water content measurements in soil and rockwool substrates: dielectric sensors for automatic in situ measurements. Acta Horticult. 304: 209-218.

Holmgren, M. Scheffer, M. and Huston, M. A. 1997. The interplay of facilitation and competition in plant communities: - Ecology 78: 1966-1975.

Hutchings, M. J. and de Kroon, H. 1994. Foraging in plants: the role of morphological plasticity in resource acquisition. - Adv. Ecol. Res. 25: 159-238.

Hutchings, M. J. and Wijesinghe, D. K. 1997. Patchy habitats, division of labour and growth dividends in clonal plants. Trends Ecol. Evol. 12: 390-394.

King, R. W., Wardlaw, I. F. and Evans, L. T. 1967. Effect of assimilate utilization on photosynthetic rate in wheat. Planta 77: 261-276.

Kollmann, R. and Schulz, A. 1993. Phloem regeneration. Progr. Bot. 54: 63-78.

Larcher, W. 1969. Anwendung und Zuverlässigkeit der Tetrazoliummethode zur Festellung von Schäden in pflanzlichen Geweben. - Mikroskopie 25: 207-218.

Larcher, W. 1994. Ökophysiologie der Pflanzen: Leben, Leistung und Streßbewältigung der Pflanzen in ihrer Umwelt. - Verlag Ulmer, Stuttgart.

Lau, R. R. and Young, D. R. 1988. Influence of physiological integration on survivorship and water relations in a clonal herb. - Ecology 69: 215-219.

Lenz, F. and Williams, C. N. 1973. Effect of fruit removal on net assimilation and gaseous diffusive resistance of soybean leaves. - Angew. Bot. 47: 57-63.

Marshall, C. 1990. Source-sink relations of interconnected ramets. - In: van Groenedael, J. and de Kroon, H. (eds), Clonal growth in plants: regulation and function. SPB Acad. Publ., The Hague, pp. 23-41.

Marshall, C. and Price, E. A. C. 1997. Sectoriality and its implications for physiological integration. - In: de Kroon, H. and van Groenendael, J. (eds), The ecology and evolution of clonal plants. Backhuys, Leiden, pp. 79-107.

Peterson, A. G. 1996. The ecological and evolutionary implications of physiological integration in clonal plants. - PhD thesis, Australian National University. 
Pitelka, L. F. and Ashmun, J. W. 1985. Physiology and integration of ramets in clonal plants. - In: Jackson, J. B C., Buss, L. W. and Cook, R. E. (eds), Population biology and evolution of clonal organisms. Yale University Press, New Haven, CT, pp. 399-435.

Potvin, C. 1993. ANOVA: experiments in controlled environments. - In: Scheiner, S. M. and Gurevitch, J. (eds) Designs and analysis of ecological experiments. Chapman \& Hall, New York, pp. 46-68.

Qureshi, F. A. and Spanner, D. C. 1971. Unidirectional movement of tracers along the stolon of Saxifraga sarmentosa. Planta 101: 133-146.

Rousi, A. 1965. Biosystematic studies in the species aggregate Potentilla anserina L. - Ann. Bot. Fenn. 2: 47-112.

Salzman, A. G. and Parker, M. A. 1985. Neighbors ameliorate local salinity stress for a rhizomatous plant in a heterogeneous environment. - Oecologia 65: 273-277.

Schulze, E. D. and Hall, A. E. 1981. Stomatal responses, water loss and $\mathrm{CO}_{2}$ assimilation rates of plants in contrasting environments. - Encyclopedia of Plant Physiology, New Series 12B: 181-230.

Shumway, S. W. 1995. Physiological integration among clonal ramets during invasion of disturbance patches in a New England salt marsh. - Ann. Bot. 76: 225-233.

Slade, A. J. and Hutchings, M. J. 1987. An analysis of the costs and benefits of physiological integration between ramets in the clonal perennial herb Glechoma hederacea. Oecologia 73: 425-431.

Sokal, R. R. and Rohlf, F. J. 1995. Biometry: the principles and practice of statistics in biological research, $3^{\text {rd }}$ ed Freeman, New York.

Stock, P. A. and Silvester, W. B. 1994. Phloem transport of recently-fixed nitrogen in the Gunnera-Nostoc symbiosis. New Phytol. 126: 259-266.

Stuefer, J. F. 1995. Separating the effects of assimilate and water integration in clonal fragments by the use of steamgirdling. - Abstracta Bot. 19: 75-81.
Stuefer, J. F. 1996. Potential and limitations of current concepts regarding the response of clonal plants to environmental heterogeneity. - Vegetatio 127: 55-70.

Stuefer, J. F. 1998. Two types of division of labour in clona plants: benefits, costs and constraints. - Persp. Plant Ecol. Evol. Syst. 1: 47-60.

Stuefer, J. F. and Hutchings, M. J. 1994 Environmental heterogeneity and clonal growth: a study of the capacity for reciprocal translocation in Glechoma hederacea L. Oecologia 100: 302-308

Stuefer, J. F., During, H. J. and de Kroon, H. 1994. High benefits of clonal integration in two stoloniferous species, in response to heterogeneous light environments. - J. Ecol. 85: $511-518$.

Stuefer, J. F., de Kroon, H. and During, H. J. 1996. Exploitation of environmental heterogeneity by spatial division of labour in a clonal plant. - Funct. Ecol. 10: 328-334.

Stuefer, J. F., During H. J. and Schieving F. 1998. A model on optimal root-shoot allocation and water transport in clonal plants. - Ecol. Modell. 111: 171-186.

Towill, L. E. and Mazur, P. 1975. Studies on the reduction of 2,3,5-triphenyltetrazolium chloride as a viability assay for plant tissue cultures. - Can. J. Bot. 53: 1097-1102.

Waite, S. 1994. Field evidence of plastic growth responses to habitat heterogeneity in the clonal herb Ranunculus repens. - Ecol. Res. 9: 311-316.

Went, F. A. F. C. 1923. Leerboek der algemene plantkunde. J.B. Wolters, Groningen.

Wolf, T. 1908. Monographie der Gattung Potentilla. - E. Schweizerbartsche Verlagsbuchhandlung, Stuttgart.

Young, D. R. and Smith, W. K. 1979. Influence of sun-flecks on the temperature and water relations of two sub-alpine understorey congeners. - Oecologia 43: 195-205.

Young, D. R. and Smith, W. K. 1980. Influence of sunlight on photosynthesis, water relations, and leaf structure in the understory species Arnica cordifolia. - Ecology 61: 1380 1390. 